\title{
Effect of pancreas transplantation on life expectancy, kidney function and quality of life in uraemic Type 1 (insulin-dependent) diabetic patients
}

\author{
A. Secchi ${ }^{1}$, V. Di Carlo ${ }^{2}$, S. Martinenghi ${ }^{1}$, E. La Rocca ${ }^{1}$, R. Caldara ${ }^{1}$, D. Spotti ${ }^{3}$, G. Slaviero ${ }^{3}$, C. Staudacher ${ }^{2}$, \\ G. Ferrari ${ }^{2}$ and G. Pozza ${ }^{1}$ \\ Departments of ${ }^{1}$ Internal Medicine, ${ }^{2}$ Surgery and ${ }^{3}$ Nephrology, Istituto Scientifico San Raffaele, Milan, Italy
}

Summary. The aim of our study was to evaluate the effects of haemodialysis, kidney transplantation and simultaneous kidney and pancreas transplantation on survival of diabetic subjects and on kidney function. 40 Type 1 (insulin-dependent) diabetic patients received a kidney transplantation: in 31 cases the kidney was transplanted simultaneously to a pancreas graft from the same donor (KP group), while in 9 cases the pancreas was not available ( $\mathrm{K}$ group). 44 uraemic Type 1(insulindependent) diabetic patients on dialysis and in waiting list for kidney transplantation, constituted the control group (HD group). Patient survival rate 1,3 and 5 years following transplantation was better in KP group $(93 \%, 89 \%, 89 \%$, respectively) than in $\mathrm{K}$ group $(88 \%$, $88 \%, 73 \%$, respectively) and in HD group $(88 \%, 62 \%$, $51 \%$, respectively). Kidney graft survival at 1,3 and 5 years post-transplant was better in KP group (93\%, $72 \%, 72 \%$, respectively) than in $\mathrm{K}$ group $(76 \%, 61 \%$, $31 \%$, respectively). 1 year after transplantation, patients of the KP group who had lost the pancreas for technical reasons (thrombosis) were included in the $\mathrm{K}$ group so as to evaluate the effect of the transplanted pancreas on long-term patient and kidney survival. Patient survival rate in the KP group (17 patients) at 2 and 4 years was $100 \%$, while at the same intervals it was $78 \%$ in the $\mathrm{K}$ group (13 patients). Kidney graft function rate at 2 and 4 years was $93 \%$ in the KP group (17 grafts) and 54\% and $27 \%$ respectively in the $\mathrm{K}$ group (14 grafts). Evaluation of quality of life in patients receiving a kidney and pancreas transplantation showed an improvement in psychological well-being, when compared to patients receiving a kidney transplantation alone. Physical well-being was similar in patients transplanted with kidney and pancreas or with kidney alone.

Key Words: Kidney transplantation - Pancreas transplantation - Life expectancy - Quality of life

\section{Introduction}

Kidney transplantation is the treatment of choice in young diabetic uraemic patients, since long-term dialysis can deteriorate the pre-existing diabetic macroangiopathy, thus reducing life expectancy. A major problem after kidney transplantation in diabetic patients is to achieve good metabolic control in patients receiving steroids. Pancreas transplantation, in association with kidney transplantation is proposed as a cure for diabetes in these patients (Sutherland 1989). The positive effect of pancreas transplantation on diabetic polyneuropathy and retinopathy remains an object of debate (Ramsay 1988; Solders 1987; Secchi 1991; Bandello 1989), while the prevention of recurrence of diabetic nephropathy on the transplanted kidney has been well demonstrated (Mauer 1989; Bilous 1989). The contrasting data reported on the effects of pancreas transplantation on long-term degenerative complications of diabetes could be the consequence of the advanced status of complications when patients undergo transplantation: it is well-known that when diabetic patients develop end-stage renal failure degenerative complications have reached the point of noreturn.

The leading causes of death in uraemic diabetic patients are vascular accidents, strictly related to the advanced degree of macro-angiopathy. Life survival in these patients, both when treated with dialysis or with kidney transplantation seems to be strictly correlated to the progression of macroangiopathy.

The aim of our study was to evaluate: 1) the influence of kidney transplantation on life survival in uraemic diabetic patients, 2) the influence of pancreas transplantation on patient survival, kidney graft function and quality of life. 


\section{Subjects and methods}

Patients. Between April 1985 and December 1990, 84 Type I (insulindependent) diabetic uraemic patients were admitted to the kidney+pancreas transplantation program of our institute. Criteria of exclusion from the program were: severe dilated cardiomyopathy, severe peripheral angiopathy, severe coronary arteries disease and psycological unrelyability.

40 patients underwent transplantation. In 31 cases it was possible to perform a simultaneous kidney+pancreas transplantation (Group KP: age 38.8 \pm 1.4 years, duration of diabetes $24.7 \pm 1.1$ years, duration of dialysis $16.9 \pm 2.1$ months ), while in 9 cases only the kidney was transplanted, due to technical reasons (Group K: age 37.5 \pm 2.5 years , duration of diabetes $21.3 \pm 2.5$ years, duration of dialysis $20.6 \pm 5.8$ ). 44 patients are currently in waiting list (group HD : age $38.9 \pm 1.3$ years, duration of diabetes $23.1 \pm 1.2$ years, dialysis duration $33.9 \pm 4.5$ months)

To evaluate the long-term effects of a functioning transplanted pancreas on kidney function, patients with a kidney graft functioning for more than 1 year were reanalyzed, and groups rearranged. Patients of the $\mathrm{K}$ group and patients of the KP group, who lost their pancreas for technical reasons (primary failure and thrombosis) within the first weeks of transplantation, constituted K(>1year) Group (13 patients). Patients of the KP Group with a kidney function longer than 1 year and without technical failure of the pancreas consituted the KP(>1year) Group (17 patients).

Surgical technique. The kidney graft was anastomozed to the iliac vessels of the recipient. The pancreas was transplanted in the contralateral iliac fossa through an anastomosis of the splenic artery and vein (segmental technique with neoprene injection: 26 cases) to the iliac vessels of the recipent (Dubernard 1978). In five cases a whole pancreas graft, with bladder diversion of the exocrine secretion was transplanted (Sollinger 1988). Patients of the HD group were treated with traditional haemodialysis (Bicarbonate or Acetate) three times weekly, and /or with more advanced techniques (biofiltration, $\mathrm{PFD}$, Haemofiltration)

Statistical analysis. The rates of survival for patients and kidney were calculated according to the actuarial method (Culter 1968). The quality of life score was analyzed by chi-sqare test.

Quality of life. Quality of life was evaluated in patients of the K and KP groups before and after transplantation. It has been conceptualised along the following major dimensions: physical well-being, social well-being and working capacity. Physical wellbeing was measured by 5 multiple choice items (patients were asked how ill they are, how much of a problem their health is, how worried they are about their health, how restricted they are in activity and how their current and pretransplant health compare) and by a score (two items), based on the difficulty experienced in specific normal activity. Social well-being was measured by three multiple choice items (patients are asked whether they take part in leisure activities, whether they have hobbies and whether they attend recreative groups). Working capacity was evaluated by asking patients whether they work (part-time or full-time work). In case of unemployment the reasons were evaluated.

\section{Results}

\section{Patient and kidney survival}

Patients survival at 1, 3 and 5 years, calculated by the actuarial method, was $88 \%, 62 \%$, and $51 \%$, respectively, in the HD group, $88 \%, 88 \%$, and $73 \%$, respectively, in the $\mathrm{K}$ group, and $93 \%, 89 \%$, and $89 \%$ in the $\mathrm{KP}$ group. The causes of death were cardiovascular diseases (13 patients in the HD group, 1 patient in the $\mathrm{K}$ group, and 2 patients in the $\mathrm{KP}$ group), infectious diseases (1 patient in the $\mathrm{K}$ group), post-surgical complications (1 patient in the KP group), hyperkaliaemia ( 5 patients in the $\mathrm{HD}$ group). Kidney graft survival at 1,3 , and 5 years was $76 \%$, $61 \%, 31 \%$, respectively, in the $\mathrm{K}$ group, while being $93 \%, 72 \%, 72 \%$, respectively, in the KP group (Fig.1).

Patient survival at 5 years was $78 \%$ in the $\mathbf{K}(>1$ year) group and $100 \%$ in the $\mathbf{K P}(>1$ year) group. The rate of kidney function at 3 and 5 years in these patients was $54 \%$ and $27 \%$,respectively, in the $\mathbf{K}$ (>1year) group, while being $93 \%$ in the KP (>1year) group. Acute kidney rejection episodes per patient were similar in the two groups $(0.88 \pm 0.20$ in the $\mathrm{KP}$ group vs $0.85 \pm 0.20$ in the $\mathrm{K}$ group): kidney biopsies showed chronic rejection in all cases of kidney failure (Fig.2)
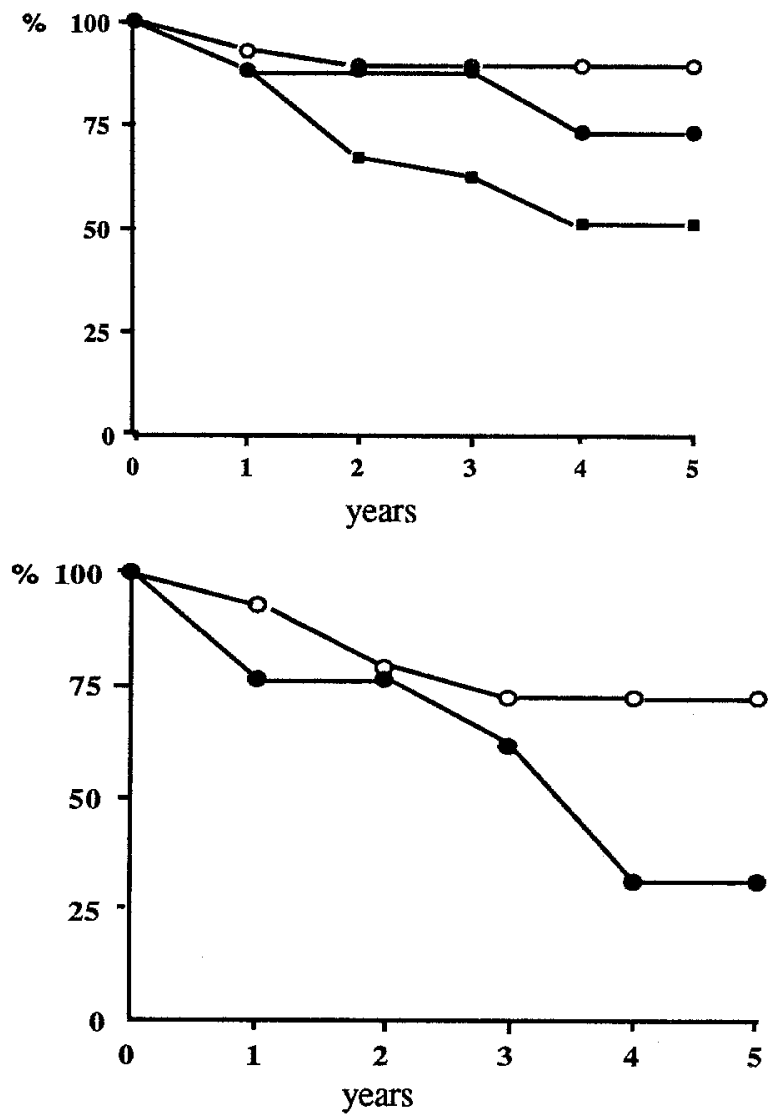

Fig.1

Upper panel. Type 1(insulin-dependent) diabetic patient survival after kidney $(9$ patients transplantation (31patients ), kidney and pancreas patients $\square$ ). Lower panel. Kidney survival after kidney ( 9 patients $\quad$ ) and simultaneous kidney and pancreas transplantation (32 patients ) ) 

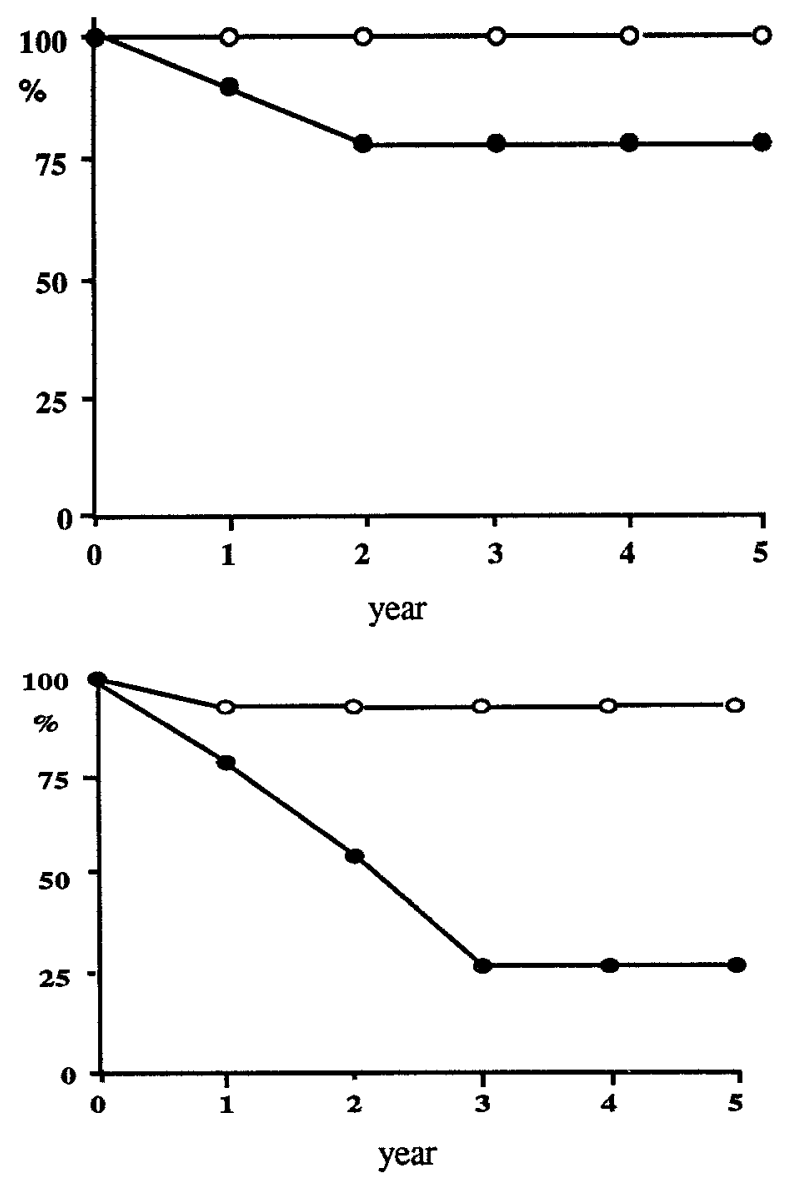

Fig. 2

Upper panel. Patient survival after kidney ( 13 patients ) and simultaneous kidney and pancreas transplantation (17 patients - ) (patients with functioning kidney for more than 1 year) Lower panel. Kidney survival after kidney (14 patients - ) and simultaneous kidney and pancreas transplantation (17 patients O)

\section{Quality of life}

Results are shown in table 1

Table 1

Quality of life

\begin{tabular}{|c|c|c|c|}
\hline & $\mathbf{K P}$ & $\mathbf{K}$ & $\mathbf{p}$ \\
\hline Feel ill & $42 \%$ & $89 \%$ & $<0.02$ \\
\hline Health is a problem & $32 \%$ & $100 \%$ & $<0.01$ \\
\hline $\begin{array}{l}\text { Limited in activity } \\
\text { Feel much better }\end{array}$ & $53 \%$ & $\mathbf{7 8 \%}$ & n.s. \\
\hline after $\mathbf{T x}$ & $84 \%$ & $77 \%$ & n.s. \\
\hline Has social activity & $89 \%$ & $56 \%$ & $<0.05$ \\
\hline Enjoy hobbies & $\mathbf{5 8 \%}$ & $22 \%$ & n.s. \\
\hline Practice sport & $21 \%$ & $33 \%$ & n.s. \\
\hline Work & $63 \%$ & $44 \%$ & n.s. \\
\hline $\begin{array}{l}\text { Not capable of } \\
\text { working }\end{array}$ & $21 \%$ & 33\% & n.s. \\
\hline
\end{tabular}

\section{Discussion}

The metabolic effects of pancreas transplantation were the object of several investigations which have shown that it is capable of leading to insulin-independence, restoring a self- regulated source of insulin which correctly responds to insulinogenic stimuli (Pozza 1983, 1985 ). In contrast, the effects of pancreas transplantation on long term degenerative complications of diabetes and its "protective" role on the transplanted kidney remain objects of discussion (Ramsay 1988;Solders 1987; Secchi 1991; Bandello 1989; Mauer 1989; Bilous 1989).

The aim of our study was to evaluate the effects of kidney and pancreas transplantation on life survival of young uraemic diabetic patients. Although this is not a prospective study, we consider correct the retrospective allocation of patients to the K, KP or HD group, since criteria of inclusion into the study were similar for all patients (eligibility to transplant program), and criteria of allocation of patients to the 3 groups $(\mathrm{K}, \mathrm{KP}, \mathrm{HD})$ were related to the possibility to receive a transplant, which is based on immunological matching. Our study has shown that kidney transplantation improves life expectancy of uremic diabetic patients ( 5 year survival: $73 \%$ vs $51 \%$ ). The association of a pancreas can further improve patient survival ( 5 years: $89 \%$ ). The leading causes of death in patients on dialysis are cariovascular accidents (13 cases: $29 \%$ of patients), while they account only for a low rate of death in $\mathrm{K}$ (1 case: $10 \%$ of patients) and in KP ( 2 cases: 6\% of patients) groups. Although other influencing factors, such as arterial hypertension, can increase the risk of cardiovascular accidents in these patients, this cannot completely explain our results, since non-diabetic patients treated with dialysis and affected by arterial hypertension, have a higher survival rate (Schleibner 1988) than diabetic patients. It is likely that the transplanted pancreas and kidney exert a protective role on the furher progression of diabetic macro-angiopathy in these patients. The role played by the transplanted pancreas on kidney survival remains unclear. From our data, when we consider patients with a kidney functioning for more than 1 year, it appears that the kidney has a longer survival when it is associated to a pancreas graft. This is not the consequence of the prevention of diabetic nephropathy on the transplanted kidney, since the histological diagnosis in all cases of renal failure was chronic rejection. We have also evaluated whether a transplanted pancreas can further improve quality of life of diabetic patients submitted to kidney transplantation, since it was previously demonstrated that a kidney transplant "per se " can improve quality of life of non-diabetic uremic patients (Simmons 1987). Only few studies are known on this subject (Nakache 1989). Our data show that diabetic patients receiving a simultaneous kidney and pancreas transplantation enjoy a better quality of life than 
diabetic patients submitted to kidney transplantation alone. This is particularly evident for the physical well being and for the social life, while working capacity and physical activities are similar in the two groups of patients. From these data it appears evident that the better quality of life enjoyed by patients receiving a pancreas and kidney transplantation is the consequence of a better psychological rather than physical condition. In conclusion kidney transplantation offer a better life expectancy than dialysis to young uremic diabetic patients. An associated pancreas transplant can further improve life expectancy in these patients. Pancreas transplantation improves quality of life of diabetic patients by improving their psychological performance.

\section{References}

Bandello F, Vigano C, Secchi A, La Rocca E, Spotti D, Caldara R, Staudacher C, Carlucci M, Castoldi R, Di Carlo V, Brancato R and Pozza G. (1989) Diabetic retinopathy in patients submitted to successful kidney-pancreas allotransplantation. Diabetes 38 , suppl 1

Biluos RW, Mauer SM, Sutherland DER, Najarian JS, Goetz FC, Steffes MW (1989) The effects of pancreas transplantation on the glomerular structure of renol allografts in patients with insulindependent diabetes. New Engl. J Med. 321, No 2:80- 85

Culter JL, Ederer F (1968) Maximum utilization of the life table method in analysing survival. J Chron. Dis 8: 699

Dubernard JM, Traeger J, Neyra P, Touraine JL, Tranchat D, Blanc Brunat N (1978) New method of preparation of a segmental pancreatic graft for transplantation. Trial in dogs and in man. Surgery 84: 633-639

Mauer SM, Goetz FC, McHugh LE, Sutherland DER, Barbosa J, Najarian IS and Steffes MW (1989) Long-term study of normal kidneys transplanted into patients with type I diabetes. Diabetes 38: 516-523

Nakache R, Tyden G, Groth CG (1989) Quality of life in diabetic patients after combined pancreas-kidney or kidney transplantation. Diabetes 38, suppl 1: 40-42

Pozza G, Bosi E, Secchi A, Piatti PM, Touraine JL, Gelet A, Pontiroli A, Dubernard JM, Traeger J (1985) Metabolic control of type1(insulin dependent) diabetes after pancreas transplantation. Br med J 291: 510-513

Pozza G, Traeger J, dubernard JM, Secchi A, Pontiroli A, Bosi E, Malik MC, Ruitton A, Blanc N (1983) Diabetologia 24: 244- 248

Ramsay RC, Goetz FC, Sutherland DER, Mauer SM, Robinson LL, Cantrill HL, Knobloch WH, Najarian JS (1988)

Progression of diabetic retinopaty after pancreas transplantation for insulin dependent diabetes mellitus. N. Eng. J. Med. J 318, No4: 208-214

Schleibner S, Welter H, Abendroth D et al (1988) Renal transplantation at the Munich transplant center: a retrspective single center review. In:Terasaki P. Clin Transpl. 107-114

Secchi A, Martinenghi S, Galardi G, Comi G, Canal N and Pozza G (1991) Effects of pancreatic transplantation on diabetic polyneuropathy. Transpl, Proc. 23, No 1: 1658-1659

Simmons RG, Abress L, Anderson CR (1988) Rehabilitation after kidney transplantation. Oragan transplantation and replacement. In:Cerilli GJ. New York Plenum

Solders G, Wilczek H, Gunnarson R, Tyden G, Persson A, Groth CG (1987) Effects of combined pancreatic and renal transplantation on diabetic neuropathy: a two year follow-up study. The Lancet 28: 1232-1235

Sollinger HW, Stratta RJ, Kalayoglu M, Pirsch JD, Belzer FO (1987) Pancreas transplantation with pancreaticocystostomy and quadruple immunosuppression. Surgery 102, No 4: 674- 679 Sutherland DER, Moudry-Munns KC, Gillingham K (1989) Pancreas transplantation: Report from the International Registry and a Preliminary Analysis of United States Results from the New United Network for Organ Sharing (UNOS) Registry. In: Terasaki P. Clinical Transplant 19-43

\author{
Dr. A.Secchi \\ Department of Internal medicine \\ Istituto Scientifico San Raffaele \\ via Olgettina 60 \\ 20132 Milan \\ Italy
}

